\title{
Morphology and physicochemical properties of starch isolated from frozen cassava root
}

\author{
Bukola I. Kayode ${ }^{\text {a }}$, Rowland M.O. Kayode ${ }^{\text {a }}$, Khadijat O. Salami ${ }^{\text {a }}$, Anthony O. Obilana ${ }^{\text {, }}$, \\ Toyosi T. George ${ }^{\mathrm{b}}$, Olayemi E. Dudu ${ }^{\mathrm{c}}$, Oluwafemi A. Adebo ${ }^{\mathrm{d}}$, Patrick B. Njobeh ${ }^{\mathrm{d}}$, \\ Siaka S. Diarra ${ }^{\mathrm{e}}$, Samson A. Oyeyinka ${ }^{\mathrm{a}, \mathrm{d}, \mathrm{e}, *}$ \\ ${ }^{\text {a }}$ Department of Home Economics and Food Science, University of Ilorin, Nigeria \\ ${ }^{\mathrm{b}}$ Department of Food Technology, Cape Peninsula University of Technology, Bellville Campus, Cape Town, South Africa \\ ${ }^{\mathrm{c}}$ Department of Chemical and Food Sciences, Bells University of Technology, Ota, Ogun State, Nigeria \\ ${ }^{\mathrm{d}}$ Department of Biotechnology and Food Technology, University of Johannesburg, Doornfontein Campus, Gauteng, South Africa \\ ${ }^{\mathrm{e}}$ School of Agriculture, Geography, Environment, Ocean and Natural Sciences, Samoa Campus, University of the South Pacific, Fiji
}

\section{A R T I C L E I N F O}

\section{Keywords:}

Cassava roots

Freezing

Functional properties

Starch

Pasting

\begin{abstract}
A B S T R A C T
Spoilage of cassava root begins immediately after harvest, but its shelf-life could be enhanced by adopting freezing as a storage method. This study investigated the physicochemical properties and morphology of starch isolated from cassava roots frozen for 0, 7, 14, 21 and 28 days. Extracted starches can be categorized as compound starches with most granules irregularly shaped, with some oval, round and truncated. The amylose contents (22.05-26.41\%) decreased with an increase in the freezing time, but the starches showed similar crystallinity pattern (Type A). Fourier infrared transform spectroscopy showed a reduction in double-helical order structure of starches from frozen cassava roots. Starches from the stored roots were generally less firm, less sticky, more cohesive and had higher peak and trough viscosities compared to starch from freshly harvested roots. Starch from frozen cassava starch may be suited for use in certain types of noodles, such as Japanese noodles due to low amylose content. Future studies are however, required to explore the starches in food applications.
\end{abstract}

\section{Introduction}

Cassava (Manihot esculenta Crantz) is an important industrial crop that serves as food for humans and animals. It is highly drought tolerant, and grows reasonably well in poor soils (Ezui, Leffelaar, Franke, Mando, \& Giller, 2018). Zhu (2015) reported that more than $80 \%$ of cassava produced in Africa is used for human food as a source of energy, with over $50 \%$ in the form of various shelf-stable products, for example, high-quality cassava flour (HQCF) (Maziya-Dixon, Alamu, Popoola, \& Yomeni, 2017; Oyeyinka, Adeloye, Smith, Adesina, \& Akinwande, 2019), roasted cassava grits, 'gari' (Balogun, Karim, Kolawole, \& Solarin, 2012; Oyeyinka, Ajayi, et al., 2019) and tapioca (Akintayo et al., 2019) These products are characterized by low moisture content which enhances stability and long-term storage (Uchechukwu-Agua, Caleb, Manley, \& Opara, 2015; Uchechukwu-Agua, Caleb, \& Opara, 2015). Another important product from cassava root with industrial relevance and application is starch. Cassava starch can be processed into different products such as biofuel (Lu, Ding, \& Wu, 2011), edible films (Orozco-Parra, Mejía, \& Villa, 2020; Schmidt, Porto, Laurindo, \& Menegalli, 2013) and tapioca (Akintayo et al., 2019). According to Dudu, Li, Oyedeji, Oyeyinka, and Ma (2019), cassava flour and starch have exceptional quality attributes with potentials in bakery applications. For food and industrial applications, the knowledge of the physicochemical properties including structure of starch are very vital. Chisenga, Workneh, Bultosa, and Alimi (2019) also noted that the application of cassava flour and starch in product development and food formulations is influenced by their composition, physicochemical and functional properties.

The physicochemical properties of cassava starch including pasting and thermal properties have been widely studied by different researchers (Cuenca, Ferrero, \& Albani, 2020; de Sena Aquino, Azevedo, Ribeiro, Costa, \& Amante, 2015; Díaz, Dini, Viña, \& García, 2018; He

\footnotetext{
* Corresponding author. Department of Home Economics and Food Science, University of Ilorin, Nigeria.

E-mail address: sartf2001@yahoo.com (S.A. Oyeyinka).
} 
et al., 2020; Oyeyinka, Salako, et al., 2020; Penido et al., 2018). These properties are influenced by factors such as; starch composition, i.e. amylose to amylopectin ratio (Hoover, Hughes, Chung, \& Liu, 2010), presence of minor non-starch components like fibres (Moorthy, George, \& Padmaja, 1993), pre-gelatinization (Wang, Wang, Song, Zhang, \& Zhang, 2018) and fermentation (Oyeyinka, Adeloye, Olaomo, \& Kayitesi, 2020). Wang et al. (2018) reported significant reduction in viscosities of pre-gelatinized cassava as well as the weakening of gel structures compared to gel produced from un-pregelatinized cassava starch. An earlier study by Moorthy et al. (1993) found that the presence of fibrous components in cassava starch increased their gelatinization temperatures.

The storage of cassava roots before starch extraction has also been found to influence the physicochemical properties of starch (Abera \& Rakshit, 2004; Osunsami, Akingbala, \& Oguntimein, 1989; Oyeyinka, Salako, et al., 2020). Abera and Rakshit (2004) found that the functional properties such as swelling power and paste clarity of starch from stored cassava chips significantly reduced with increasing storage time. The suitable storage (controlled atmosphere, refrigeration, freezing, and waxing) of cassava root after harvest is important to prevent microbiological and physiological changes that takes place after harvest (Sánchez et al., 2013; Uarrota et al., 2016). According to Oyeyinka, Ajayi, et al. (2019), if these changes are not monitored and controlled through appropriate storage, the quality of resulting products can be negatively affected. Previous studies reported that the spoilage of cassava root can be prevented to a certain extent by storing the roots under a controlled atmosphere condition (Uchechukwu-Agua, Caleb, Manley, \& Opara, 2015), waxing (Nuwamanya et al., 2019), refrigeration (Oyeyinka, Salako, et al., 2020; Uchechukwu-Agua, Caleb, \& Opara, 2015) and freezing (Uchechukwu-Agua, Caleb, \& Opara, 2015). Freezing seems to be the best method of preservation of foods since water is practically immobile and unavailable for enzymatic changes within the food structure, although it may result in damage of tissues in cassava roots.

Due to the rapid deterioration of cassava roots, our research team focused on preserving the roots through low-temperature storage and subsequently evaluating the properties of products from the stored roots. For example, gari has been successfully prepared from frozen (Oyeyinka, Ajayi, et al., 2019) and refrigerated cassava (Oyeyinka, Adesoye, et al., 2020), while the quality of cooked paste (Oyeyinka, Ayinla, et al., 2020), custard (Ogundele et al., 2020) and starch from refrigerated cassava root has also been documented (Oyeyinka, Salako, et al., 2020).

Several of the studies reported above have shown the potentials of low-temperature storage such as refrigeration and freezing in extending the keeping quality of cassava roots. These studies also documented the quality of products like gari from refrigerated and frozen cassava, starch, cooked paste and custard from refrigerated cassava. A study by Oyeyinka, Salako, et al. (2020) showed that refrigeration of cassava root did not alter the crystalline pattern (type A) of the isolated starch but resulted in a reduction in starch granule size and an increase in peak, setback, breakdown and final viscosities. Since the application of freezing for the storage of cassava roots to reduce its postharvest loss during marketing has been suggested (Wijesinghe \& Sarananda, 2010), there is the need to also evaluate and document the quality of products such as starch from the frozen roots. This is particularly important because cassava stands out among the underutilized starch sources because of its wide availability, comparatively higher starch content and ease of extraction of its starch (Chisenga et al., 2019). Hence, this study aims to investigate the physicochemical properties of starch isolated from cassava roots frozen for 28 days. Starch obtained from cassava roots that were freshly harvested and processed the same day served as the control.

\section{Materials and methods}

\subsection{Materials}

One hundred kilograms (100 kg) of matured cassava roots (TMS 98/ 0581) with an average moisture content of $61 \pm 2 \%$, were carefully harvested at 10 months after planting in December 2019 from International Fund for Agricultural Development cassava plantation farm at Offa town, Kwara State, Nigeria.

\subsection{Freezing of cassava roots}

The roots were cleaned by washing under running water. The washed roots were peeled, re-washed, drained and $5 \mathrm{~kg}$ each of the tubers were packed in Ziploc bags and frozen at $-20 \pm 1{ }^{\circ} \mathrm{C}$ in a LED deep freezer (Model GR-K35DSLBC, LG, Korea) within a period of $1 \mathrm{~h}$ of rapid freezing and maintained for 7, 14, 21 and 28 days. Starch extracted from freshly harvested cassava roots which was processed same day was included as the reference sample.

\subsection{Thawing and starch extraction}

Starch was extracted and dried as earlier described with slight modifications (Osunsami et al., 1989). Briefly, the frozen cassava roots were transferred after the required storage period into a refrigerator working at $4{ }^{\circ} \mathrm{C}$ to thaw overnight. Thawed cassava roots were grated using a grating machine powered by Lister Diesel engine (5-1 6HP 650RPM, UK). The grated pulp was suspended in $140 \mathrm{~L}$ of distilled water for $2 \mathrm{~h}$ and then strained through a fine mesh (aperture size: $350 \mu \mathrm{m}$ ). The resulting starch milk was allowed to settle in clean plastic buckets for $4 \mathrm{~h}$ and the clean supernatant liquid was decanted. The sedimented starch was further washed several times with distilled to get rid of adhering proteins. Starch samples were oven-dried at $50{ }^{\circ} \mathrm{C}$ for $24 \mathrm{~h}$. Dried samples were milled, sieved (sieve size of $180 \mu \mathrm{m}$ ), packed in Ziploc bags and stored under refrigeration at $4{ }^{\circ} \mathrm{C}$ until analysis, for a maximum of one week. Extracted starches were labelled CS0, CS7, CS14, CS21 and CS28 for starch from cassava root frozen for $0,7,14,21$ and 28 days, respectively. The proximate composition of the starch including ash, protein, fibre, fats and total carbohydrate were determined as previously reported (Corgneau et al., 2019).

\subsection{Colour, morphology and apparent amylose contents}

To assess the purity of the extracted starches, the Hunterlab color parameters $\left(\mathrm{L}^{*}, \mathrm{a}^{*}\right.$ and $\left.\mathrm{b}^{*}\right)$ of the starches were measured using a Colorflex-EZ spectrophotometer (A60-1014-593, Hunter Associates, Reston, VA, USA). The $L^{*}$ value indicate lightness $(0-100)$, positive $a^{*}$ $\left(+a^{*}\right)$ indicate redness, negative $a^{*}\left(-a^{*}\right)$ : greenness, positive $b^{*}\left(+b^{*}\right)$ : yellowness and negative $b^{*}\left(-b^{*}\right)$ : blueness.

The total colour change $(\Delta \mathrm{E})$ was calculated using the equation below (Falade \& Oyeyinka, 2015).

$\Delta E=\sqrt{(\Delta L)^{2}+(\Delta a)^{2}+(\Delta b)^{2}}$

Granule size and shape were determined under a scanning electron microscope (JAM-540, JEOL, Tokyo, Japan). The starch samples were mounted on a plate with adhesive tape and gold-coated. Starch samples were viewed at a resolution of $1500 \times$ magnification. The apparent amylose content of cassava starch was determined by a colorimetric method (Naidoo, Amonsou, \& Oyeyinka, 2015).

\subsection{X-ray diffraction (XRD)}

The crystalline pattern of the starch samples was examined using a diffractometer (PANanalytical, Eindhoven, North Brabant, Netherlands) as earlier reported (Wokadala, Ray, \& Emmambux, 2012). Starches were 
equilibrated at $25{ }^{\circ} \mathrm{C}$ and relative humidity of $100 \%$, in an incubator (MTIE10, Labcon, Pretoria, South Africa) for $12 \mathrm{~h}$ before measurement. The relative crystallinity was calculated using the equation given below.

$\mathrm{RC}(\%)=\frac{100 A c}{A c+A a}$

where Ac is the crystalline area and Aa is the amorphous area on the Xray diffractogram.

\subsection{Fourier transform infrared spectroscopy (FTIR)}

The ordered structure of starch was analyzed using a spectrometer (4100-JASCO Spectrometer, Japan) as reported by Man et al. (2012). The spectra were obtained in the transmittance mode with 64 scans from 500 to $4000 \mathrm{~cm}^{-1}$.

\subsection{Functional properties}

The water absorption capacities and swelling power of the starch samples were determined using the method described by Oyeyinka, Adeloye, Olaomo, and Kayitesi (2020).

\subsection{Pasting properties}

The pasting properties of the starch samples were measured using a Rapid Visco-Analyzer (RVA 4500, Perten Instruments, Sydney, NSW, Australia) following the method reported by Oyeyinka, Adeloye, et al. (2020).

\subsection{Textural analysis}

The textural properties of starch gels was measured using a Universal Testing Machine (Testometric, M500-100AT, Lincoln, England) as previously reported with slight modifications Shaikh, Ali, and Hasnain (2015). Starch pastes were formed by cooking starch in water $(10 \%$ $\mathrm{w} / \mathrm{w}$ ) at $95{ }^{\circ} \mathrm{C}$ for $15 \mathrm{~min}$. Cooked starch pastes were cooled and stored at $4{ }^{\circ} \mathrm{C}$ for $24 \mathrm{~h}$ before analyses. Gels were covered with a film to prevent loss of moisture and were compressed to $50 \%$ of the original size at a speed of $2 \mathrm{~mm} / \mathrm{s}$. Texture profile parameters (adhesiveness, chewiness, cohesiveness, gumminess, hardness and springiness) were calculated using the computer software.

\subsection{Statistical analysis}

Duplicate samples were prepared and all analyses were done in triplicate. Data obtained from the experiments were statistically analyzed and expressed as mean \pm standard deviation. A one-way analysis of variance (ANOVA) and Fisher Least Significant Difference (LSD) were computed using SPSS Version 21.0 (SPSS Inc., Chicago, IL, USA) with a statistical significance of $\mathrm{p}<0.05$. Further statistical assessment was done using the Pearson correlation (SPSS Inc., Chicago, IL, USA) to establish the relationship among the functional, pasting and textural properties.

\section{Results and discussion}

\subsection{Starch composition and colour}

Extracted starch showed low fat (average of $0.12 \%$ ) and protein (average of $0.27 \%$ ) contents, but no ash and fibre were detected in the samples (Table 1). These minute non-starch components are generally used to ascertain the purity of starch. Previous studies also indicated that cassava starch contain minor components such as protein, lipid, fiber and phosphorus, but these components can interfere with the physicochemical properties of the extracted starch (Chisenga et al., 2019). The total starch content varied between 87.43 and $89.64 \%$, which agrees with the values (65.00-99.14\%) reported in the literature (Pereira \& Leonel, 2014; Sánchez et al., 2009; Vatanasuchart, Niyomwit, \& Wongkrajang, 2009).

The apparent amylose content of the starch samples significantly ( $\mathrm{p}$ $\leq 0.05$ ) decreased from $26.41 \%$ to $22.05 \%$ with increasing freezing period (Table 1). There was approximately 6, 7, 12 and $17 \%$ decrease in the apparent amylose content for starch isolated from cassava frozen for $7,14,21$ and 28 days, respectively. Freezing is known to make water immobile and thus limit enzyme activity. Hence, the reduction in apparent amylose content after freezing can be due to changes that occur in the roots during thawing rather than during freezing. Freezing and thawing cycles reportedly affected the activities of $\alpha$-amylase, bile-saltactivated lipase and trypsin extracted from gilthead sea bream (Sparus aurata) stored for 2 years (Solovyev \& Gisbert, 2016). Whittam and Rosano (1973) had earlier reported that the freezing and thawing rate, especially when slow, is highly detrimental to purified $\alpha$-amylase activity in an aqueous solution than the faster process. Hence, the slow thawing rate used in this study may have encouraged the activity of the amylase enzyme to begin the degradation of amylose in the roots and this may explain the reduction in the measured amylose content. Sánchez et al. (2013) noted that enzymatic hydrolysis can modify the ratio of amylose to amylopectin in the starch granules and the modification may significantly impact the physicochemical properties of starch. The values of amylose (22.05-26.41\%) in this study agrees with previous reports on cassava starch (Chandanasree, Gul, \& Riar, 2016; Nwokocha, Aviara, Senan, \& Williams, 2009; Tappiban et al., 2020; Zhu, 2015).

Cassava starches exhibited slight differences in their Hunter lab colour properties (Table 1 ). The $L^{*}$ values of the isolated starches generally decreased, while the redness $\left(\mathrm{a}^{*}\right)$ and yellowness $\left(\mathrm{b}^{*}\right)$ values increased significantly with increasing freezing period. Although the $\mathrm{L}^{*}$ values decreased, the decrease was insignificant $(p>0.05)$ beyond 7 days of freezing. A similar result was reported for starch from refrigerated cassava roots, albeit for 3 weeks (Oyeyinka, Salako, et al., 2020). The calculated total colour change $(\Delta \mathrm{E})$ of the starches ranged from 0.22 to 3.11 for starch from cassava root frozen for 7 days and 28 days, respectively (Table 1 ). The $\Delta \mathrm{E}$ values were determined relative to the control starch and agree with the $L^{*}$ values which also decreased with storage period. Variation in the colour of the starch may be explained by the changes that took place during thawing and subsequent drying of the starches. Earlier studies similarly found significant colour change in starch from stored cassava (Osunsami et al., 1989).

Table 1

Chemical composition and colour parameters of starch from frozen cassava roots.

\begin{tabular}{|c|c|c|c|c|c|c|c|c|}
\hline Storage period (days) & Fat $(\%)$ & Protein (\%) & Total starch (\%) & Apparent amylose (\%) & $L^{*}$ & $a^{*}$ & $b^{*}$ & $\Delta \mathrm{E}$ \\
\hline 0 & $0.13^{\mathrm{a}} \pm 0.01$ & $0.40^{\mathrm{a}} \pm 0.07$ & $87.44^{c} \pm 0.12$ & $26.41^{\mathrm{a}} \pm 0.13$ & $83.63^{\mathrm{a}} \pm 0.64$ & $3.10^{c} \pm 0.03$ & $9.80^{c} \pm 0.03$ & - \\
\hline 7 & $0.12^{\mathrm{a}} \pm 0.01$ & $0.23^{\mathrm{b}} \pm 0.01$ & $89.18^{\mathrm{b}} \pm 0.04$ & $24.89^{\mathrm{ab}} \pm 0.16$ & $83.55^{\mathrm{a}} \pm 0.54$ & $3.18^{\mathrm{b}} \pm 0.01$ & $9.99^{b} \pm 0.04$ & $0.22^{c} \pm 0.14$ \\
\hline 14 & $0.14^{\mathrm{a}} \pm 0.01$ & $0.27^{\mathrm{b}} \pm 0.00$ & $89.54^{\mathrm{ab}} \pm 0.08$ & $24.67^{\mathrm{b}} \pm 0.38$ & $81.87^{b} \pm 0.40$ & $3.25^{\mathrm{b}} \pm 0.06$ & $10.06^{\mathrm{b}} \pm 0.03$ & $1.85^{\mathrm{b}} \pm 0.13$ \\
\hline 21 & $0.11^{\mathrm{a}} \pm 0.03$ & $0.23^{\mathrm{b}} \pm 0.01$ & $89.26^{\mathrm{b}} \pm 0.27$ & $23.23^{\mathrm{bc}} \pm 0.35$ & $80.74^{b} \pm 0.25$ & $3.97^{\mathrm{a}} \pm 0.00$ & $10.48^{\mathrm{a}} \pm 0.07$ & $3.09^{\mathrm{a}} \pm 0.09$ \\
\hline 28 & $0.12^{\mathrm{a}} \pm 0.01$ & $0.23^{\mathrm{b}} \pm 0.00$ & $89.64^{a} \pm 0.08$ & $22.05^{c} \pm 1.34$ & $80.73^{b} \pm 0.23$ & $3.98^{\mathrm{a}} \pm 0.01$ & $10.51^{\mathrm{a}} \pm 0.11$ & $3.11^{\mathrm{a}} \pm 0.11$ \\
\hline
\end{tabular}

Mean \pm SD Mean with different superscript in each column are significantly different $(\mathrm{p}<0.05)$.

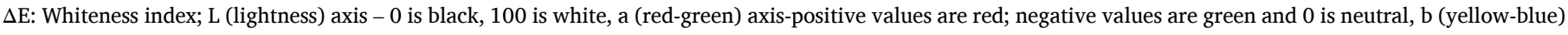
axis-positive values are yellow; negative values are blue and 0 is neutral. 


\subsection{Morphology}

Isolated starch samples had similar shape but different granule size (Fig. 1). Freezing of the cassava roots appears not to change the starch granule morphology. Most of the granules were irregular and truncated in shape, while a few round and oval-shaped granules were also seen. The starches showed an average granule size ranging between 6 and 22 $\mu \mathrm{m}$. The size and shape of the cassava starches are in agreement with previous studies (Fang, He, Jiang, Li, \& Li, 2020; He et al., 2020; Oyeyinka, Adeloye, et al., 2019; Oyeyinka, Adeloye, et al., 2020; Oyeyinka, Salako, et al., 2020; Rolland-Sabaté et al., 2012).

\subsection{Crystallinity pattern}

All the extracted starches showed similar crystallinity patterns with strong peaks at $15^{\circ}(2 \Theta)$, a doublet at $17^{\circ}$ and $18^{\circ}(2 \Theta)$ and a single peak at $23^{\circ}(2 \Theta)$, indicating the A-type crystallinity pattern (Fig. 2). The similarity in the patterns observed from the diffractograms suggests that freezing of cassava roots did not affect the crystalline structure of the extracted starches. Starch generally will display different crystallinity patterns ( $\mathrm{A}, \mathrm{B}$ or $\mathrm{C}$ ), depending on the arrangement of the crystalline lamellae of amylopectin, the source (botanical origin) of the starch and in some instances the conditions of experiment. Cassava starch generally has been found to exhibit the A-type crystallinity (He et al., 2020; Oyeyinka, Salako, et al., 2020; Wang et al., 2018) or the $\mathrm{C}_{\mathrm{A}}$-type (Rolland-Sabaté et al., 2013; Rolland-Sabaté et al., 2012). The $\mathrm{C}_{\mathrm{A}}$-type denotes the portion of A-type is dominant over B-type in the polymorphic composition (Zhu, 2015). However, the C-type crystalline type, which is very unusual for roots and tubers has been observed in cassava starch by some researchers (Fang et al., 2020). The difference observed in the crystal type of starch may be due to several factors including botanical source and the method of analysis. For instance, an increase in starch moisture content resulted in a change of the A-type polymorph to the C-type pattern (da Cruz Francisco, Silverio, Eliasson, \& Larsson, 1996). The relative crystallinity (RC) of freshly harvested cassava starch was $38.63 \%$ (Table 2). Freezing increased the RC of cassava starch

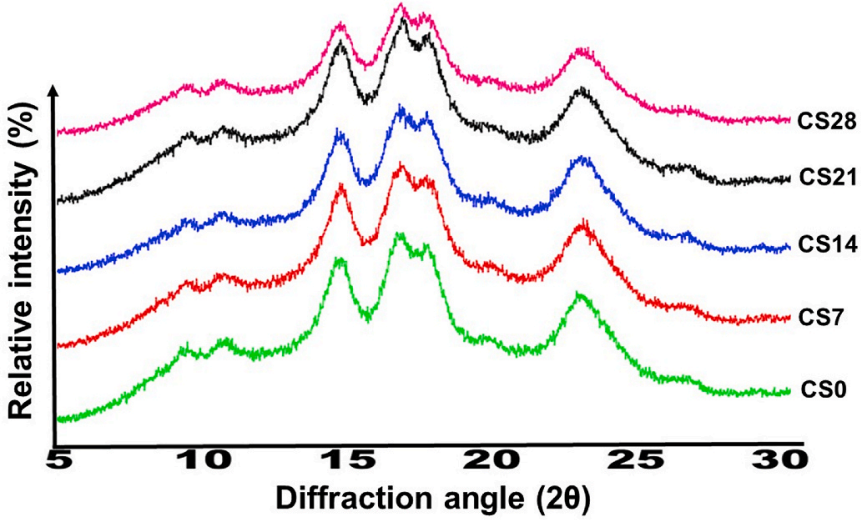

Fig. 2. XRD of starches extracted from frozen cassava root.

CS0: Starch from freshly harvested cassava roots; CS7: Starch from cassava root frozen for 7 days; CS14: Starch from cassava root frozen for 14 days; CS21: Starch from cassava root frozen for 21 days; CS28: Starch from cassava root frozen for 28 days.

which varied from $40.76 \%$ to $42.28 \%$ (day 28 and day 14 , respectively) and may be due to the reduction of the amylose content (Table 1), indicating a reduction in the amorphous region of starch. Further to this is the possibility of the formation of new starch crystallites by increasing the perfection of smaller crystalline structures of native cassava starch into larger ones as previously noted (Dudu et al., 2019).

\subsection{Fourier transform infrared spectroscopy (FTIR)}

The FTIR spectra for starch from freshly harvested cassava and from frozen cassava roots were similar (Fig. 3). All the starch samples showed peaks in the broadband region of $3000-3650 \mathrm{~cm}^{-1}$, corresponding to the complex vibration stretching of free, inter-and intra-molecular hydroxyl (-OH) groups (Guo, Kong, Du, \& Xu, 2019; Pozo et al., 2018). The starches showed differences in their peak intensities (14 days $>21$ days
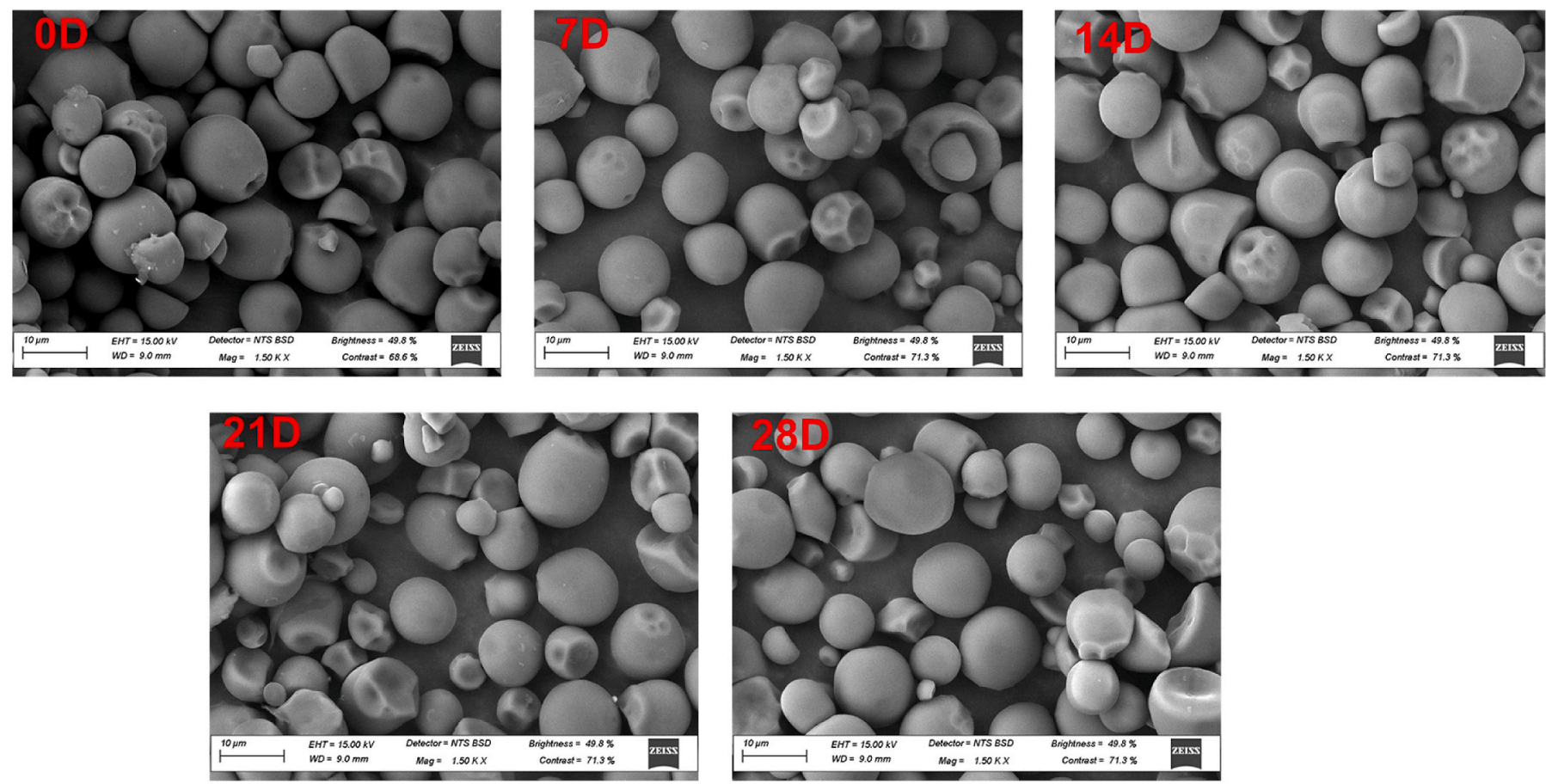

Fig. 1. Scanning electron micrographs of starch isolated from frozen cassava roots.

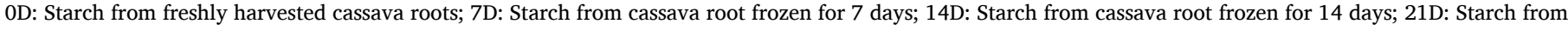
cassava roots frozen for 21 days; 28D: Starch from cassava roots frozen for 28 days. 
Table 2

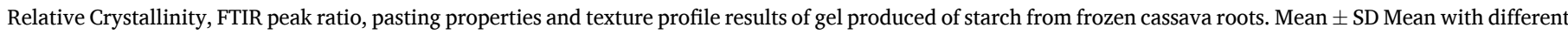
superscript in each row are significantly different $(\mathrm{p}<0.05)$.

\begin{tabular}{|c|c|c|c|c|c|}
\hline \multirow[t]{2}{*}{ Parameters } & \multicolumn{5}{|c|}{ Storage period (days) } \\
\hline & 0 & 7 & 14 & 21 & 28 \\
\hline Relative crystallinity (\%) & $38.63^{c} \pm 0.42$ & $41.43^{b} \pm 0.46$ & $42.28^{\mathrm{a}} \pm 0.15$ & $42.07^{\mathrm{a}} \pm 0.12$ & $40.76^{\mathrm{ab}} \pm 0.45$ \\
\hline Ratio of $1045 / 1022 \mathrm{~cm}^{-1}$ & $0.99^{\mathrm{a}} \pm 0.01$ & $0.92^{\mathrm{d}} \pm 0.01$ & $0.97^{\mathrm{b}} \pm 0.01$ & $0.96^{\mathrm{bc}} \pm 0.01$ & $0.95^{c} \pm 0.01$ \\
\hline PV (RVU) & $484.42^{\mathrm{b}} \pm 9.54$ & $487.62^{\mathrm{ab}} \pm 6.08$ & $453.91^{b} \pm 6.83$ & $496.33^{c} \pm 4.49$ & $522.04^{\mathrm{a}} \pm 8.08$ \\
\hline TV (RVU) & $163.33^{\mathrm{b}} \pm 4.47$ & $175.67^{\mathrm{a}} \pm 7.19$ & $162.54^{\mathrm{b}} \pm 2.53$ & $169.88^{\mathrm{ab}} \pm 4.77$ & $180.96^{\mathrm{a}} \pm 1.82$ \\
\hline BV (RVU) & $321.09^{\mathrm{ab}} \pm 5.06$ & $311.96^{\mathrm{bc}} \pm 8.89$ & $291.38^{c} \pm 8.30$ & $246.46^{\mathrm{d}} \pm 9.72$ & $341.08^{\mathrm{a}} \pm 6.26$ \\
\hline FV (RVU) & $266.42^{\mathrm{ab}} \pm 8.01$ & $278.08^{\mathrm{a}} \pm 5.30$ & $256.16^{\mathrm{b}} \pm 4.71$ & $258.88^{\mathrm{b}} \pm 0.64$ & $278.96^{\mathrm{a}} \pm 0.41$ \\
\hline SV(RVU) & $103.08^{\mathrm{a}} \pm 3.53$ & $93.58^{\mathrm{cd}} \pm 2.23$ & $93.63^{\mathrm{cd}} \pm 2.18$ & $89.00^{\mathrm{d}} \pm 5.41$ & $98.00^{\mathrm{b}} \pm 0.04$ \\
\hline Peak time (min) & $3.84^{\mathrm{c}} \pm 0.04$ & $4.04^{b} \pm 0.00$ & $4.27^{\mathrm{a}} \pm 0.09$ & $4.14^{\mathrm{ab}} \pm 0.09$ & $3.80^{c} \pm 0.04$ \\
\hline PT $\left({ }^{\circ} \mathrm{C}\right)$ & $72.25^{b c} \pm 0.63$ & $72.80^{\mathrm{ab}} \pm 0.53$ & $73.18^{\mathrm{ab}} \pm 0.60$ & $73.52^{\mathrm{a}} \pm 0.03$ & $71.43^{c} \pm 0.63$ \\
\hline Adhesiveness (N.s) & $1.50^{\mathrm{a}} \pm 0.01$ & $1.14^{\mathrm{ab}} \pm 0.63$ & $0.54^{\mathrm{bc}} \pm 0.03$ & $0.54^{\mathrm{bc}} \pm 0.28$ & $0.15^{c} \pm 0.15$ \\
\hline Cohesiveness & $0.70^{\mathrm{b}} \pm 0.05$ & $0.93^{\mathrm{a}} \pm 0.01$ & $0.82^{\mathrm{ab}} \pm 0.08$ & $0.91^{\mathrm{a}} \pm 0.04$ & $0.92^{\mathrm{a}} \pm 0.00$ \\
\hline Chewiness (N) & $3.24^{\mathrm{a}} \pm 0.00$ & $3.18^{\mathrm{a}} \pm 1.40$ & $2.99^{\mathrm{a}} \pm 1.22$ & $3.84^{\mathrm{a}} \pm 0.00$ & $3.17^{\mathrm{a}} \pm 0.72$ \\
\hline Gumminess (N) & $4.77^{\mathrm{a}} \pm 0.17$ & $3.77^{\mathrm{a}} \pm 1.34$ & $4.07^{\mathrm{a}} \pm 1.07$ & $4.68^{\mathrm{a}} \pm 0.63$ & $3.16^{\mathrm{a}} \pm 0.71$ \\
\hline Hardness $(\mathrm{N})$ & $6.85^{\mathrm{a}} \pm 0.79$ & $4.06^{\mathrm{b}} \pm 1.51$ & $4.92^{\mathrm{ab}} \pm 0.77$ & $5.19^{\mathrm{ab}} \pm 0.95$ & $3.45^{\mathrm{b}} \pm 0.77$ \\
\hline Springiness & $0.68^{b} \pm 0.02$ & $0.83^{b} \pm 0.07$ & $0.72^{\mathrm{b}} \pm 0.11$ & $0.82^{\mathrm{b}} \pm 0.04$ & $1.00^{\mathrm{a}} \pm 0.00$ \\
\hline
\end{tabular}

Mean \pm SD Mean with different superscript in each row are significantly different $(\mathrm{p}<0.05)$.

PV: Peak Viscosity; TV: Trough Viscosity; BV: Breakdown Viscosity; FV: Final Viscosity; SV: Setback Viscosity; PT: Pasting Temperature.

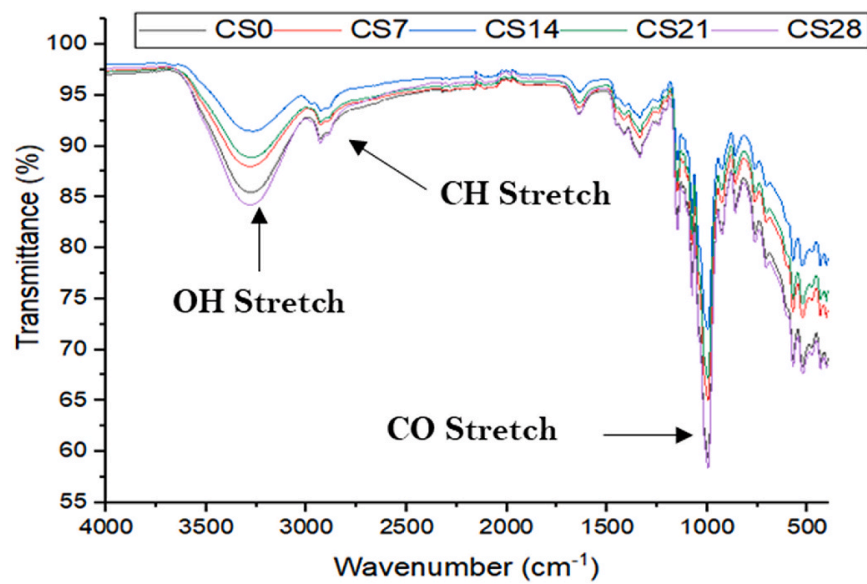

Fig. 3. FTIR spectra of starches extracted from frozen cassava root. CS0: Starch from freshly harvested cassava roots; CS7: Starch from cassava root frozen for 7 days; CS14: Starch from cassava root frozen for 14 days; CS21: Starch from cassava root frozen for 21 days; CS28: Starch from cassava root frozen for 28 days.

$>7$ days $>0$ days $>28$ days) in this region. These variation could be attributed to differences in the strength of hydrogen bonds within the starch structure (Kong, Lee, Kim, \& Ziegler, 2014; Pozo et al., 2018). Furthermore, all the starches showed an absorption peak at around $2931 \mathrm{~cm}^{-1}$ attributed to the stretching of the $\mathrm{C}-\mathrm{H}$ bonds associated with the ring methine hydrogen atoms (Guo et al., 2019). The starch samples also displayed a sharp peak at around $995 \mathrm{~cm}^{-1}$ in the fingerprint region which denotes the vibrations of the glucose $\mathrm{C}-\mathrm{O}-\mathrm{C}$ bond in the starch structure (Estrada-León et al., 2016; Oyeyinka, Salako, et al., 2020).

To assess the effect of freezing on the short-range structure of starch, the bands at 1045 and $1022 \mathrm{~cm}^{-1}$ which are linked with the crystalline and amorphous regions in starch, respectively were determined and their ratio reported in Table 2. The ratio of these bands (1045/1022 $\mathrm{cm}^{-1}$ ) has been widely used to quantify the degree of crystalline order in starch samples (Babu, Mohan, \& Parimalavalli, 2019; Ji et al., 2019; Man et al., 2012). Starches from frozen cassava root generally showed significantly $\left(\mathrm{p}<0.05\right.$ ) lower $1045 / 1022 \mathrm{~cm}^{-1}$ ratios $(0.92-0.97)$ than starch from freshly harvested cassava root $(0.99)$ as shown in Table 2. The observed ratio suggests that freezing resulted in the reduction of the double-helical order structure of the starch granules in the external region (Zhang et al., 2020) and this may explain variation in the functional and pasting properties as will be discussed later.

\subsection{Functional properties}

The water absorption capacity (WAC) of the starch samples were higher than their oil absorption capacity (OAC) (Fig. 4). This is expected since starch are hydrophilic and the mechanism of oil absorption simply relies on physical entrapment rather than absorption into the starch granules. Freezing of the cassava roots did not significantly $(p \geq 0.05)$ influence the WAC and OAC of the extracted starches, though these parameters increased slightly with the storage period. Amylose content of starches has been suggested to influence their ability to absorb water. For example, Bambara groundnut genotype with high amylose content reportedly showed restricted swelling but greater ability to absorb water compared with genotypes with low amylose content (Oyeyinka, Singh, Adebola, Gerrano, \& Amonsou, 2015). In this study, the amylose content of the extracted starches reduced with an increase in the freezing period and hence shows no clear correlation with WAC. Other researchers associated variation in WAC to factors such as damaged starch content, starch granular morphology features and fine structure of starch (Liu et al., 2014; Ma et al., 2016).

Hence, the slight differences in WAC may be explained by variation in the starch granule size (Fig. 1) and possibly the increase in relative crystallinity (Table 2).

Extracted starches showed similar swelling pattern with an increase

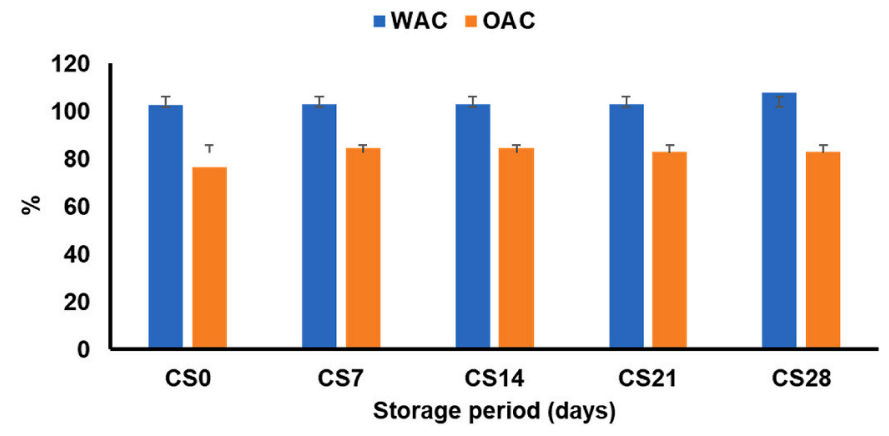

Fig. 4. Water and oil absorption capacities of starch.

WAC: Water absorption capacity; OAC: Oil absorption capacity; CS0: Starch from freshly harvested cassava roots; CS7: Starch from cassava root frozen for 7 days; CS14: Starch from cassava root frozen for 14 days; CS21: Starch from cassava root frozen for 21 days; CS28: Starch from cassava root frozen for 28 days. 
in swelling as a function of temperature (Fig. 5). The swelling power of the starches increased drastically between temperatures of 60 and $70^{\circ} \mathrm{C}$, indicating the gelatinization of starch. Previous researchers (Rolland-Sabaté et al., 2012, 2013; Tappiban et al., 2020; Zhu, 2015) on cassava starch, reported a gelatinization temperature ranging between approximately 56 and $75{ }^{\circ} \mathrm{C}$. Furthermore, starches from frozen cassava showed significantly $(\mathrm{p}<0.05)$ higher swelling power than the control starch samples and this may be explained by the variation in amylose content of the starches (Table 1). Amylose in starch is known to restrict starch swelling (Naidoo et al., 2015) by forming a barrier around the starch granules (Sang, Bean, Seib, Pedersen, \& Shi, 2008). Other factors which may influence the swelling properties of starch are the structure of amylopectin and the extent of interaction within the crystalline and amorphous regions of starch (Singh, Singh, Kaur, Sodhi, \& Gill, 2003).

\subsection{Pasting properties}

The average pasting temperature (approx. $73^{\circ} \mathrm{C}$ ) of the starches (Table 2) is in agreement with values $\left(58-86^{\circ} \mathrm{C}\right)$ reported in the literature for cassava starch (Abera \& Rakshit, 2004; Dudu et al., 2019; Gomand, Lamberts, Visser, \& Delcour, 2010; Oyeyinka, Salako, et al., 2020; Zhu, 2015). Pasting temperature is the amount of energy required to cook the starch samples. Freezing of cassava roots had very minimal effect on the pasting temperature since the values were very similar.

The peak viscosity, which signifies the ability of starches to swell varied between 453.91 and $522.04 \mathrm{RVU}$, trough viscosity ranged from 162.54 to $180.96 \mathrm{RVU}$, breakdown viscosity ranged between 246.46 and $341.08 \mathrm{RVU}$, final viscosity varied from 256.16 to $278.96 \mathrm{RVU}$ and setback viscosity ranged between 89.00 and 103.08 RVU. Starch from frozen cassava roots generally displayed a higher peak viscosity compared with the control starch sample. The difference in peak viscosity of the starches could be due to the variation in their amylose contents (Table 1 ) and an increase in relative crystallinity of the starches (Table 2). Previous studies indicated that amylose in starch restricts swelling (Naidoo et al., 2015) and forms a barrier around the granules during pasting (Sang et al., 2008). The peak viscosity result agrees with studies on physicochemical properties of starch from cassava roots stored at room temperature (Sánchez et al., 2013) or refrigeration temperature (Oyeyinka, Salako, et al., 2020).

Another important pasting property of starch is the setback viscosity as it relates to the level of retrogradation in the starch during storage. Generally, starch from frozen roots showed significantly lower setback viscosities (89.00-98.00 RVU) compared with starch from freshly harvested roots (103.08 RVU). Retrogradation occurs when amylose is free

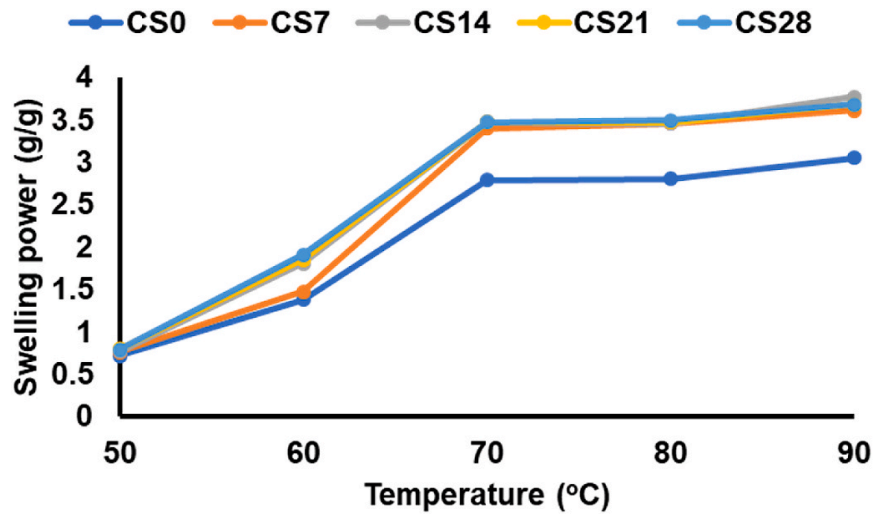

Fig. 5. Swelling power of starch.

Errors bars indicate standard deviation $(\mathrm{N}=4)$.

CS0: Starch from freshly harvested cassava roots; CS7: Starch from cassava root frozen for 7 days; CS14: Starch from cassava root frozen for 14 days; CS21: Starch from cassava root frozen for 21 days; CS28: Starch from cassava root frozen for 28 days. to re-associate into crystallites (Liang, King, \& Shih, 2002). In baked foods, a lower rate of retrogradation is desirable especially for foods like bread that are usually consumed in a very short time and a high rate of retrogradation has detrimental effect on the sensory properties of baked goods (Wang, Li, Copeland, Niu, \& Wang, 2015). Hence, the lower setback viscosity of the starch from frozen cassava suggests their potentials in baking applications.

\subsection{Texture of starch gels}

The textural properties of cassava starch gels determined using a texture analyser are presented in Table 2 . Freezing of the cassava root did not significantly $(\mathrm{p} \geq 0.05)$ affect the chewiness $(2.99-3.84 \mathrm{~N}$ ), cohesiveness (0.70-0.93), and gumminess (3.16-4.77 N) of the gels prepared from the starches. However, the adhesiveness, hardness and springiness were significantly $(\mathrm{p}<0.05)$ affected. While the adhesiveness $(0.15-1.50 \mathrm{~N} \mathrm{~s})$ and hardness $(3.45-6.85 \mathrm{~N})$ decreased, the springiness (0.68-1.00) increased with an increase in the freezing period. The reduction in adhesiveness and hardness values for gels prepared from starch extracted from stored roots indicates the gels were less sticky and softer, respectively compared to gel from the control starch sample. Waxy starch produces gels which are less firm than normal starch gels because the presence of amylose between the amylopectin chains in the latter increases the close-packing and bonding of the gel (Liu, Ramsden, \& Corke, 1999). Thus, high amylose starch form harder gels and a reduction in gel adhesiveness and hardness may be associated with the reduction in amylose content of the starch samples (Table 1) and an increase in the relative crystallinity (Table 2). Starches with higher amylose content reportedly showed higher firmness (hardness) than starches with low amylose (Chung et al., 1998; Oyeyinka, Singh, Venter, \& Amonsou, 2017). Collado, Mabesa, and Corke (1999) reported that the adhesiveness of potato starch negatively correlated with the amylose content. Since the starch gels were stored before texture profile measurement, the hardness may be linked with the retrogradation of amylose and amylopectin in the cassava starches, resulting from the re-association of amylose-amylose chains and amylopectin chains to form junction zones through cross-links (Wang et al., 2015). The reduction in the ratios of FTIR peaks at 1045 and1022 $\mathrm{cm}^{-1}$ (Table 1) may further explain the reduction in the starch hardness since these peaks are very sensitive to changes in starch structure. Rapid freezing has also been found to reduce the hardness and adhesiveness of rice during storage (Yu, Ma, \& Sun, 2010). Starch gel textural features are very important parameters that can be used to determine the potential use of starches in various food applications.

\subsection{Pearson correlation among functional pasting and textural properties}

Pearson correlation of the water absorption capacity, oil absorption capacity, amylose content, pasting properties, i.e., pasting temperature, peak time, peak, trough, breakdown, final and setback viscosities as well as the measured textural properties (hardness, springiness, adhesives, cohesiveness, chewiness and gumminess) of the starch gel are shown in Table 3 . The amylose content showed a significant but negative correlation with peak viscosity $(\mathrm{r}=-0.60, \mathrm{p}<0.01)$, trough viscosity $(\mathrm{r}=$ $-0.67, \mathrm{p}<0.01)$, springiness $(\mathrm{r}=-0.79, \mathrm{p}<0.05)$ and cohesiveness $(\mathrm{r}$ $=-0.69, \mathrm{p}<0.01)$ but positively correlated with adhesiveness $(\mathrm{r}=$ $0.82, \mathrm{p}<0.05)$ and hardness $(\mathrm{r}=0.67, \mathrm{p}<0.01)$ of the starches. Hardness or firmness of starch gels has been linked with the amylose content of starch and a positive correlation in this study also confirms the role of amylose in gel formation. The significant positive correlation of amylose with the peak viscosity in this study further confirms the role of amylose in swelling properties of starch. Amylose has been suggested to form a barrier around starch granules which restricts swelling behaviour (Naidoo et al., 2015). Amylose content of root and tuber starches such as potato starch has been positively correlated with the adhesiveness of the starch gel and negatively correlated with the 


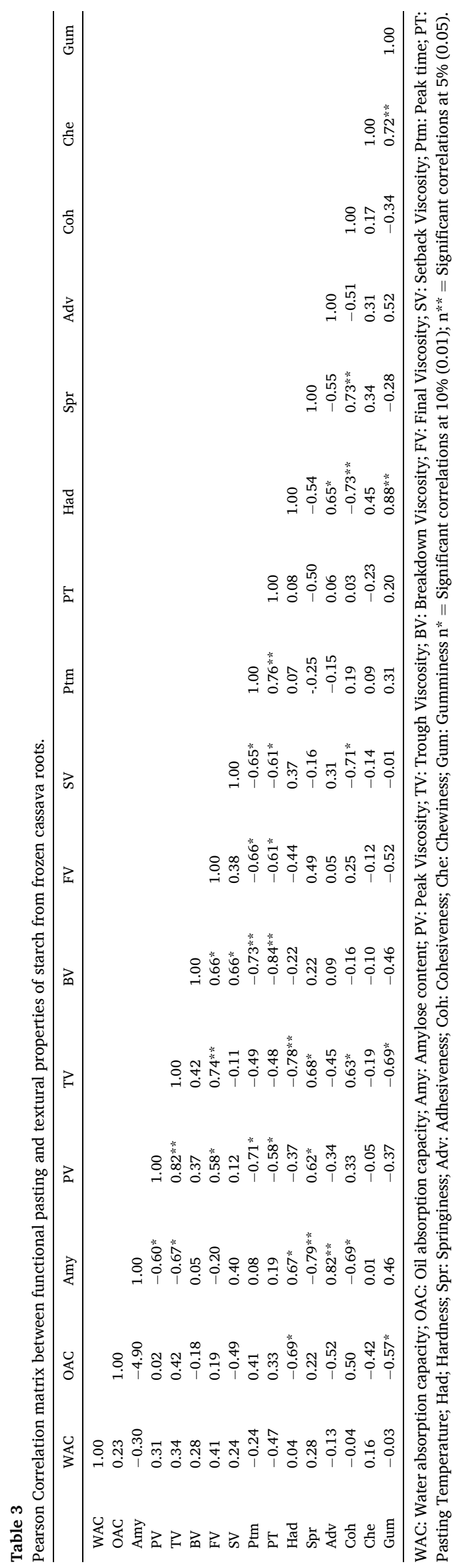

cohesiveness and springiness (Ye, Xiao, Zhou, \& Zhao, 2019). The peak viscosity positively correlated with the trough viscosity $(r=0.82, p<$ $0.05)$, final viscosity $(r=0.58, p<0.01)$ and springiness $(r=0.62, p<$ $0.01)$ but negatively correlated with peak time $(\mathrm{r}=0.71, \mathrm{p}<0.01)$ and pasting temperature $(r=0.58, p<0.01)$. Trough viscosity which indicates the disruption of starch granules from the effects of shear and heat showed a significant positive correlation with final viscosity $(\mathrm{r}=$ $0.74, \mathrm{p}<0.05)$, springiness $(\mathrm{r}=0.68, \mathrm{p}<0.01)$ and cohesiveness $(\mathrm{r}=$ $0.63, \mathrm{p}<0.01)$. However, the trough viscosity negatively correlated with the hardness $(r=-0.78, p<0.05)$ and gumminess $(r=-0.69, p<$ 0.01 ) of the starch gel (Table 3 ). Breakdown viscosity displayed a significant positive correlation with final viscosity $(r=0.66, p<0.05)$ and setback viscosity $(\mathrm{r}=0.66, \mathrm{p}<0.01)$ but negatively with peak time $(\mathrm{r}=$ $-0.73, \mathrm{p}<0.05)$ and pasting temperature $(\mathrm{r}=-0.84, \mathrm{p}<0.05)$. The observed negative correlation of breakdown viscosity with pasting temperature suggests better thermal stability of the starches extracted from frozen cassava root. Starches with high breakdown viscosity are less thermally stable and would disintegrate during thermal processing. The poor resistance of native starch to shear and high temperatures has been the basis for modification using physical, chemical, enzymatic, genetic methods and a combination of these techniques. Hardness of the gel correlated with the adhesiveness $(r=0.65, p<0.01)$, gumminess $(r$ $=0.88, \mathrm{p}<0.05)$ and cohesiveness $(\mathrm{r}=-0.73, \mathrm{p}<0.05)$, while springiness correlated positively with cohesiveness $(r=0.73, p<0.05)$. The chewiness of the starch gel also positively correlated with the gumminess $(\mathrm{r}=0.72, \mathrm{p}<0.05)$.

\section{Conclusion}

This study investigated the structural, functional and pasting properties of starch isolated from cassava roots frozen for 0, 7, 14, 21 and 28 days. Freezing did not affect starch granule size, crystalline pattern, but resulted in a decrease in amylose content and facilitated the formation of new crystallites. Cassava starch consists of mainly irregular and truncated shaped granules. The peak and trough viscosities of starches from stored roots increased but the setback and breakdown viscosities decreased. Starches from frozen cassava were less firm and less sticky but more cohesive than starch from freshly harvested roots. Pasting temperatures were not substantially affected by freezing. Amylose content, followed by peak viscosity, trough and breakdown viscosities demonstrated more significant correlations at $5 \%(\mathrm{p}<0.05)$ and $10 \%$ level ( $\mathrm{p}<0.01$ ) with other functional, pasting and textural properties. Further studies are required to determine the application of these starches in the food industry such as in custard production, bioplastic packaging and as thickeners or stabilizers in food systems.

\section{CRediT authorship contribution statement}

Bukola I. Kayode: Data curation, Writing - original draft. Rowland M.O. Kayode: Supervision, Data curation. Khadijat O. Salami: Methodology, Validation. Anthony O. Obilana: Writing - review \& editing, Writing - original draft. Toyosi T. George: Data curation, Formal analysis. Olayemi E. Dudu: Data curation, Formal analysis, Writing review \& editing, and review of draft manuscript. Oluwafemi A. Adebo: Writing - review \& editing, Review of draft manuscript and editing. Patrick B. Njobeh: Supervision, Writing - review \& editing, and review of draft manuscript. Siaka S. Diarra: Writing - review \& editing, Review of draft manuscript and editing. Samson A. Oyeyinka: Conceptualization, Supervision, Data curation, Formal analysis, reading of draft and final manuscript.

\section{Declaration of competing interest}

The authors declare that they have no known competing financial interests or personal relationships that could have appeared to influence the work reported in this paper. 


\section{Acknowledgement}

Dr Samson Oyeyinka is grateful to the University of Johannesburg, South Africa for the Faculty-University Research Committee Fellowship.

\section{References}

Abera, S., \& Rakshit, S. K. (2004). Effect of dry cassava chip storage on yield and functional properties of extracted starch. Starch Staerke, 56, 232-240.

Akintayo, O. A., Obadu, J. M., Karim, O. R., Balogun, M. A., Kolawole, F. L., \& Oyeyinka, S. A. (2019). Effect of replacement of cassava starch with sweet potato starch on the functional, pasting and sensory properties of tapioca grits. LWT-Food Science and Technology, 111, 513-519.

Babu, A. S., Mohan, R. J., \& Parimalavalli, R. (2019). Effect of single and dualmodifications on stability and structural characteristics of foxtail millet starch. Food Chemistry, 271, 457-465.

Balogun, M., Karim, O., Kolawole, F., \& Solarin, A. (2012). Quality attributes of tapioca meal fortified with defatted soy flour. Agros, 12, 61-68.

Chandanasree, D., Gul, K., \& Riar, C. (2016). Effect of hydrocolloids and dry heat modification on physicochemical, thermal, pasting and morphological characteristics of cassava (Manihot esculenta) starch. Food Hydrocolloids, 52, 175-182.

Chisenga, S. M., Workneh, T. S., Bultosa, G., \& Alimi, B. A. (2019). Progress in research and applications of cassava flour and starch: A review. Journal of Food Science \& Technology, 56, 2799-2813.

Chung, H., Cho, S., Chung, J., Shin, T., Son, H., \& Lim, S.-T. (1998). Physical and molecular characteristics of cowpea and acorn starches in comparison with corn and potato starches. Food Science and Biotechnology, 7, 269-275.

Collado, L. S., Mabesa, R., \& Corke, H. (1999). Genetic variation in the physical properties of sweet potato starch. Journal of Agricultural and Food Chemistry, 47, 4195-4201.

Corgneau, M., Gaiani, C., Petit, J., Nikolova, Y., Banon, S., Ritié-Pertusa, L., et al. (2019). Digestibility of common native starches with reference to starch granule size, shape and surface features towards guidelines for starch-containing food products. International Journal of Food Science and Technology, 54, 2132-2140.

da Cruz Francisco, J., Silverio, J., Eliasson, A.-C., \& Larsson, K. (1996). A comparative study of gelatinization of cassava and potato starch in an aqueous lipid phase (L2) compared to water. Food Hydrocolloids, 10, 317-322.

Cuenca, P., Ferrero, S., \& Albani, O. (2020). Preparation and characterization of cassava starch acetate with high substitution degree. Food Hydrocolloids, 100, Article 105430.

Díaz, A., Dini, C., Viña, S. Z., \& García, M. A. (2018). Technological properties of sour cassava starches: Effect of fermentation and drying processes. LebensmittelWissenschaft \& Technologie, 93, 116-123.

Dudu, O. E., Li, L., Oyedeji, A. B., Oyeyinka, S. A., \& Ma, Y. (2019). Structural and functional characteristics of optimised dry-heat-moisture treated cassava flour and starch. International Journal of Biological Macromolecules, 133, 1219-1227.

Estrada-León, R., Moo-Huchin, V., Ríos-Soberanis, C., Betancur-Ancona, D., MayHernández, L., Carrillo-Sánchez, F., et al. (2016). The effect of isolation method on properties of parota (Enterolobium cyclocarpum) starch. Food Hydrocolloids, 57, 1-9.

Ezui, K., Leffelaar, P., Franke, A., Mando, A., \& Giller, K. (2018). Simulating drought impact and mitigation in cassava using the LINTUL model. Field Crops Research, 219, 256-272.

Falade, K. O., \& Oyeyinka, S. A. (2015). Color, chemical and functional properties of plantain cultivars and cooking banana flour as affected by drying method and maturity. Journal of Food Processing and Preservation, 39, 816-828.

Fang, K., He, W., Jiang, Y., Li, K., \& Li, J. (2020). Preparation, characterization and physicochemical properties of cassava starch-ferulic acid complexes by mechanical activation. International Journal of Biological Macromolecules, 160, 482-488.

Gomand, S. V., Lamberts, L., Visser, R. G. F., \& Delcour, J. A. (2010). Physicochemical properties of potato and cassava starches and their mutants in relation to their structural properties. Food Hydrocolloids, 24, 424-433.

Guo, J., Kong, L., Du, B., \& Xu, B. (2019). Morphological and physicochemical characterization of starches isolated from chestnuts cultivated in different regions of China. International Journal of Biological Macromolecules, 130, 357-368.

He, R., Fu, N.-F., Chen, H.-M., Ye, J.-Q., Chen, L.-Z., Pu, Y.-F., et al. (2020). Comparison of the structural characterizatics and physicochemical properties of starches from sixteen cassava germplasms cultivated in China. International Journal of Food Properties, 23, 693-707.

Hoover, R., Hughes, T., Chung, H., \& Liu, Q. (2010). Composition, molecular structure, properties, and modification of pulse starches: A review. Food Research International, 43, 399-413.

Ji, N., Ge, S., Li, M., Wang, Y., Xiong, L., Qiu, L., et al. (2019). Effect of annealing on the structural and physicochemical properties of waxy rice starch nanoparticles: Effect of annealing on the properties of starch nanoparticles. Food Chemistry, 286, 17-21.

Kong, L., Lee, C., Kim, S. H., \& Ziegler, G. R. (2014). Characterization of starch polymorphic structures using vibrational sum frequency generation spectroscopy. The Journal of Physical Chemistry B, 118, 1775-1783.

Liang, X., King, J. M., \& Shih, F. F. (2002). Pasting property differences of commercial and isolated rice starch with added lipids and $\beta$-cyclodextrin. Cereal Chemistry, 79, 812-818.

Liu, C., Li, L., Hong, J., Zheng, X., Bian, K., Sun, Y., et al. (2014). Effect of mechanically damaged starch on wheat flour, noodle and steamed bread making quality. International Journal of Food Science and Technology, 49, 253-260.
Liu, H., Ramsden, L., \& Corke, H. (1999). Physical properties of cross-linked and acetylated normal and waxy rice starch. Starch Staerke, 51, 249-252.

Lu, Y., Ding, Y., \& Wu, Q. (2011). Simultaneous saccharification of cassava starch and fermentation of algae for biodiesel production. Journal of Applied Phycology, 23, $115-121$.

Ma, S., Li, L., Wang, X.-X., Zheng, X.-1., Bian, K., \& Bao, Q.-d. (2016). Effect of mechanically damaged starch from wheat flour on the quality of frozen dough and steamed bread. Food Chemistry, 202, 120-124.

Man, J., Cai, J., Cai, C., Xu, B., Huai, H., \& Wei, C. (2012). Comparison of physicochemical properties of starches from seed and rhizome of lotus. Carbohydrate Polymers, 88, 676-683.

Maziya-Dixon, B., Alamu, E. O., Popoola, I. O., \& Yomeni, M. (2017). Nutritional and sensory properties: Snack food made from high-quality cassava flour and legume blend. Food Sciences and Nutrition, 5, 805-811.

Moorthy, S. N., George, M., \& Padmaja, G. (1993). Functional properties of the starchy flour extracted from cassava on fermentation with a mixed culture inoculum. Journal of the Science of Food and Agriculture, 61, 443-447.

Naidoo, K., Amonsou, E., \& Oyeyinka, S. (2015). In vitro digestibility and some physicochemical properties of starch from wild and cultivated amadumbe corms. Carbohydrate Polymers, 125, 9-15.

Nuwamanya, E., Acheng, S., Vuzi, P., Muyinza, H., Matovu, M., Atwijukire, E., et al. (2019). Effectiveness of pruning and waxing in reducing postharvest physiological deterioration in Uganda local cassava varieties. African Crop Science Journal, 27, 237-251.

Nwokocha, L. M., Aviara, N. A., Senan, C., \& Williams, P. A. (2009). A comparative study of some properties of cassava (Manihot esculenta, Crantz) and cocoyam (Colocasia esculenta, Linn) starches. Carbohydrate Polymers, 76, 362-367.

Ogundele, O. M., Muazu, S. T., Oyedeji, A. B., Kayitesi, E., Njobeh, P. B., \& Oyeyinka, S. A. (2020). Chemical, functional, pasting and sensory properties of custard from refrigerated cassava root. British Food Journal, 123, 509-519.

Orozco-Parra, J., Mejía, C. M., \& Villa, C. C. (2020). Development of a bioactive synbiotic edible film based on cassava starch, inulin, and Lactobacillus casei. Food Hydrocolloids, 104, Article 105754.

Osunsami, A., Akingbala, J., \& Oguntimein, G. (1989). Effect of storage on starch content and modification of cassava starch. Starch Staerke, 41, 54-57.

Oyeyinka, S. A., Adeloye, A. A., Olaomo, O. O., \& Kayitesi, E. (2020). Effect of fermentation time on physicochemical properties of starch extracted from cassava root. Food Bioscience, 33, Article 100485.

Oyeyinka, S., Adeloye, A., Smith, S., Adesina, B., \& Akinwande, F. (2019). Physicochemical properties of flour and starch from two cassava varieties. Agros, 19, $28-45$.

Oyeyinka, S. A., Adesoye, A. A., Oladipo, J. O., Akintayo, O. A., Adediran, O. J., Badmos, A. A., et al. (2020). Physical, chemical and sensory properties of flakes (gari) prepared from refrigerated cassava roots. Agros, 20, 118-132.

Oyeyinka, S. A., Ajayi, O. I., Gbadebo, C. T., Kayode, R. M., Karim, O. R., \& Adeloye, A. A. (2019). Physicochemical properties of gari prepared from frozen cassava roots. LWTFood Science and Technology, 99, 594-599.

Oyeyinka, S. A., Ayinla, S. O., Sanusi, C. T., Akintayo, O. A., Oyedeji, A. B., Oladipo, J. O., et al. (2020). Chemical and physicochemical properties of fermented flour from refrigerated cassava root and sensory properties of its cooked paste. Journal of Food Processing and Preservation, 44, Article e14684, 14610.11111/ jfpp. 14684.

Oyeyinka, S. A., Salako, M. O., Akintayo, O., A, A., Nidoni, U., Dudu, O. R., et al. (2020). Structural, functional and pasting properties of starch from refrigerated cassava root. Journal of Food Processing and Preservation, 44, Article e14476.

Oyeyinka, S. A., Singh, S., Adebola, P. O., Gerrano, A. S., \& Amonsou, E. O. (2015). Physicochemical properties of starches with variable amylose contents extracted from Bambara groundnut genotypes. Carbohydrate Polymers, 133, 171-178.

Oyeyinka, S. A., Singh, S., Venter, S. L., \& Amonsou, E. O. (2017). Effect of lipid types on complexation and some physicochemical properties of Bambara groundnut starch. Starch Staerke, 69, Article 1600158.

Penido, F. C. L., Piló, F. B., de Cicco Sandes, S. H., Nunes, Á. C., Colen, G., de Souza Oliveira, E., et al. (2018). Selection of starter cultures for the production of sour cassava starch in a pilot-scale fermentation process. Brazilian Journal of Microbiology, $49,823-831$.

Pereira, B. L. B., \& Leonel, M. (2014). Resistant starch in cassava products. Food Science and Technology, 34, 298-302.

Pozo, C., Rodríguez-Llamazares, S., Bouza, R., Barral, L., Castaño, J., Müller, N., et al. (2018). Study of the structural order of native starch granules using combined FTIR and XRD analysis. Journal of Polymer Research, 25, 266.

Rolland-Sabaté, A., Sanchez, T., Buléon, A., Colonna, P., Ceballos, H., Zhao, S.-S., et al. (2013). Molecular and supra-molecular structure of waxy starches developed from cassava (Manihot esculenta Crantz). Carbohydrate Polymers, 92, 1451-1462.

Rolland-Sabaté, A., Sánchez, T., Buléon, A., Colonna, P., Jaillais, B., Ceballos, H., et al. (2012). Structural characterization of novel cassava starches with low and highamylose contents in comparison with other commercial sources. Food Hydrocolloids, 27, 161-174.

Sánchez, T., Dufour, D., Moreno, J., Pizarro, M., Aragón, I., Dominguez, M., et al. (2013). Changes in extended shelf life of cassava roots during storage in ambient conditions. Postharvest Biology and Technology, 86, 520-528.

Sánchez, T., Salcedo, E., Ceballos, H., Dufour, D., Mafla, G., Morante, N., et al. (2009). Screening of starch quality traits in cassava (Manihot esculenta Crantz). Starch Staerke, 61, 12-19.

Sang, Y., Bean, S., Seib, P. A., Pedersen, J., \& Shi, Y.-C. (2008). Structure and functional properties of sorghum starches differing in amylose content. Journal of Agricultural and Food Chemistry, 56, 6680-6685. 
Schmidt, V. C. R., Porto, L. M., Laurindo, J. B., \& Menegalli, F. C. (2013). Water vapor barrier and mechanical properties of starch films containing stearic acid. Industrial Crops and Products, 41, 227-234.

de Sena Aquino, A. C. M., Azevedo, M. S., Ribeiro, D. H. B., Costa, A. C. O., \& Amante, E. R. (2015). Validation of HPLC and CE methods for determination of organic acids in sour cassava starch wastewater. Food Chemistry, 172, 725-730.

Shaikh, M., Ali, T. M., \& Hasnain, A. (2015). Post succinylation effects on morphological, functional and textural characteristics of acid-thinned pearl millet starches. Journal of Cereal Science, 63, 57-63.

Singh, N., Singh, J., Kaur, L., Sodhi, N. S., \& Gill, B. S. (2003). Morphological, thermal and rheological properties of starches from different botanical sources. Food Chemistry, 81, 219-231.

Solovyev, M., \& Gisbert, E. (2016). Influence of time, storage temperature and freeze/ thaw cycles on the activity of digestive enzymes from gilthead sea bream (Sparus aurata). Fish Physiology and Biochemistry, 42, 1383-1394.

Tappiban, P., Sraphet, S., Srisawad, N., Wu, P., Han, H., Smith, D. R., et al. (2020). Effects of cassava variety and growth location on starch fine structure and physicochemical properties. Food Hydrocolloids, 108, Article 106074.

Uarrota, V. G., Moresco, R., Schmidt, E. C., Bouzon, Z. L., da Costa Nunes, E., de Oliveira Neubert, E., et al. (2016). The role of ascorbate peroxidase, guaiacol peroxidase, and polysaccharides in cassava (Manihot esculenta Crantz) roots under postharvest physiological deterioration. Food Chemistry, 197, 737-746.

Uchechukwu-Agua, A. D., Caleb, O. J., Manley, M., \& Opara, U. L. (2015). Effects of storage conditions and duration on physicochemical and microbial quality of the flour of two cassava cultivars (TME 419 and UMUCASS 36). CyTA - Journal of Food, 13, 635-645.

Uchechukwu-Agua, A. D., Caleb, O. J., \& Opara, U. L. (2015). Postharvest handling and storage of fresh cassava root and products: A review. Food and Bioprocess Technology, 8, 729-748.
Vatanasuchart, N., Niyomwit, B., \& Wongkrajang, K. (2009). Resistant starch contents and the in vitro starch digestibility of Thai starchy foods. Kasetsart Journal of Natural Sciences, 43, 178-186.

Wang, S., Li, C., Copeland, L., Niu, Q., \& Wang, S. (2015). Starch retrogradation: A comprehensive review. Comprehensive Reviews in Food Science and Food Safety, 14, 568-585.

Wang, X., Wang, H., Song, J., Zhang, Y., \& Zhang, H. (2018). Understanding the structural characteristics, pasting and rheological behaviours of pregelatinised cassava starch. International Journal of Food Science and Technology, 53, 2173-2180.

Whittam, J. H., \& Rosano, H. L. (1973). Effects of the freeze-thaw process on $\alpha$ amylase. Cryobiology, 10, 240-243.

Wijesinghe, W., \& Sarananda, K. (2010). Utilization of cassava through freezing. Journal of Food \& Agriculture, 1, 17-29.

Wokadala, O. C., Ray, S. S., \& Emmambux, M. N. (2012). Occurrence of amylose-lipid complexes in teff and maize starch biphasic pastes. Carbohydrate Polymers, 90, 616-622.

Ye, F., Xiao, L., Zhou, Y., \& Zhao, G. (2019). Spontaneous fermentation tunes the physicochemical properties of sweet potato starch by modifying the structure of starch molecules. Carbohydrate Polymers, 213, 79-88.

Yu, S., Ma, Y., \& Sun, D.-W. (2010). Effects of freezing rates on starch retrogradation and textural properties of cooked rice during storage. LWT-Food Science and Technology, $43,1138-1143$.

Zhang, C., Zhou, L., Lu, Y., Yang, Y., Feng, L., Hao, W., et al. (2020). Changes in the physicochemical properties and starch structures of rice grains upon pre-harvest sprouting. Carbohydrate Polymers, 234, 115893.

Zhu, F. (2015). Composition, structure, physicochemical properties, and modifications of cassava starch. Carbohydrate Polymers, 122, 456-480. 